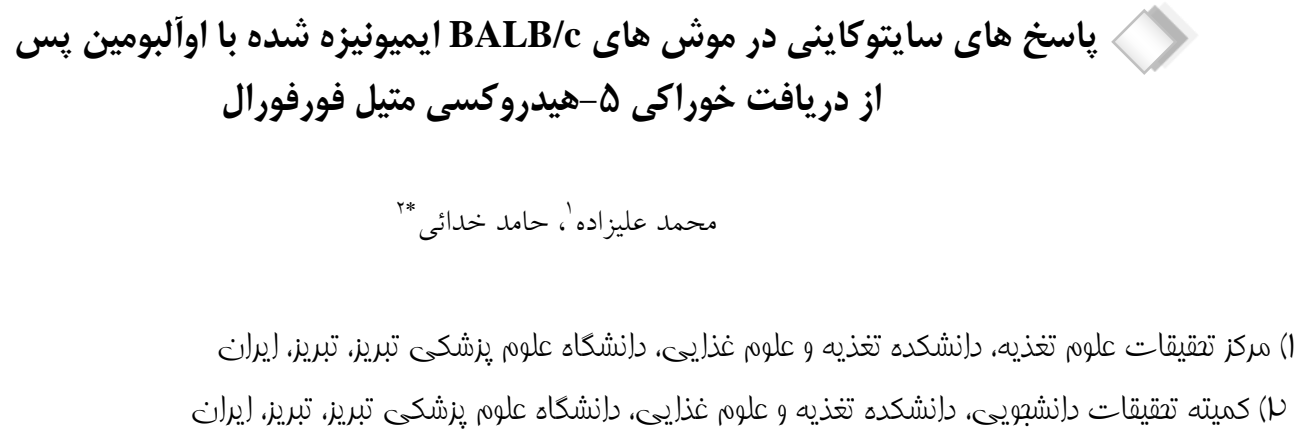

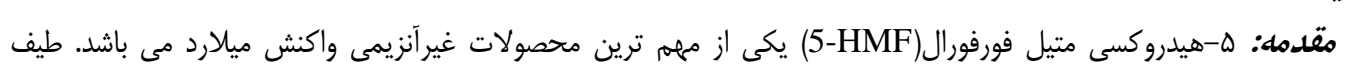

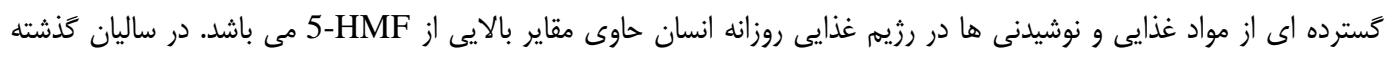

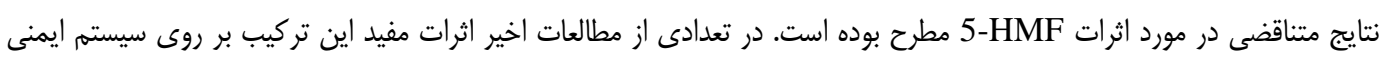

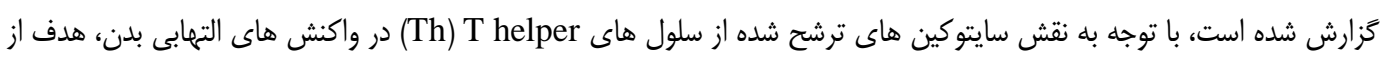

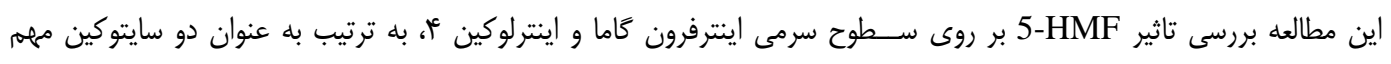

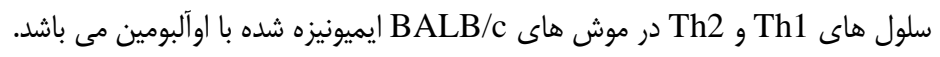

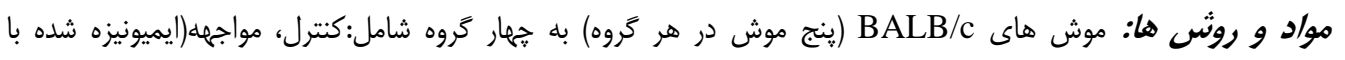

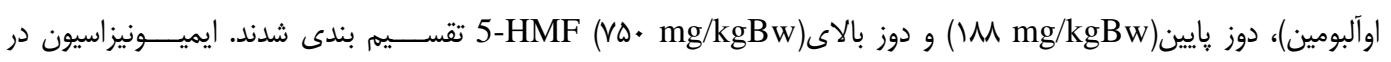

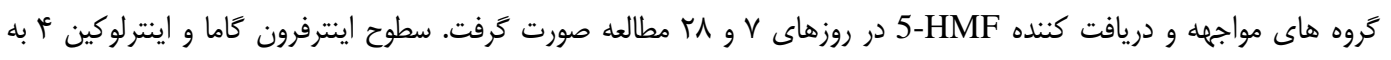

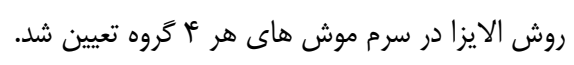

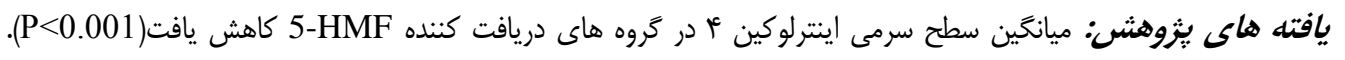

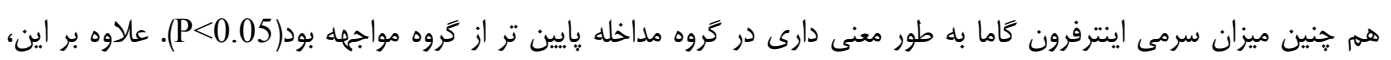

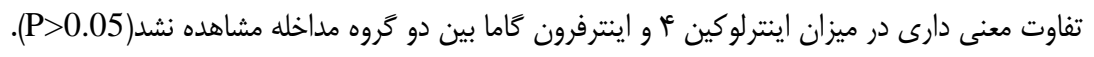

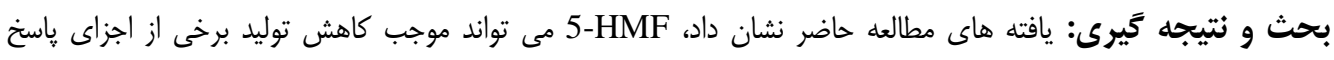

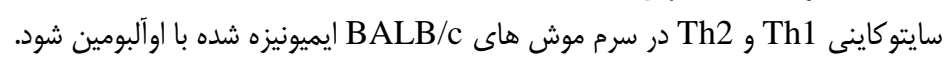

$$
\text { وازه هاى كليدى: ه-هيدروكسى متيل فورفورال، اوآلبومين، سايتوكاين }
$$

* نويسنده مسئول: كميته تحقيقات دانشجويى، دانشكده تغذيه و علوم غذايى، دانشخاه علوم بزشكى تبريز، تبريز، ايران Email: hamedkhodaeii@yahoo.com

Copyright (C) 2018 Journal of Ilam University of Medical Science. This is an open-access article distributed under the terms of the Creative Commons Attribution international 4.0 International License (https://creativecommons.org/licenses/by-nc/4.0/) which permits copy and redistribute the material, in any medium or format, provided the original work is properly cited. 
سايتوكــاين ها مورد استفاده قرار كرفته است كه با

عوارض بسيارى در بيماران همراه بوده اند(1). (1). مي باشد 5-HMF

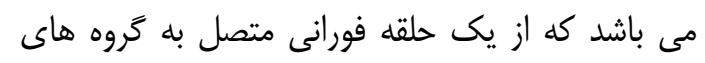

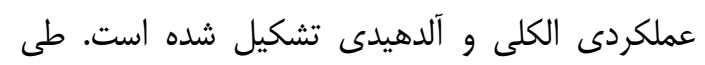

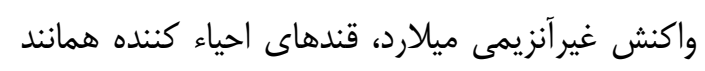

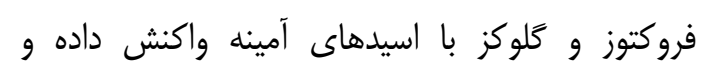
محصول اصلى واكنش 5-HMF تشكيل مى شود (r) ا).

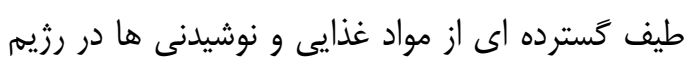

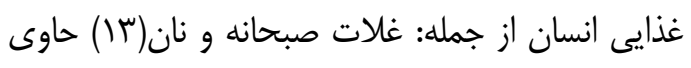

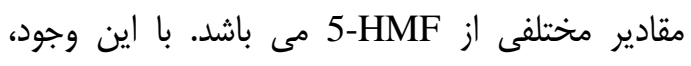

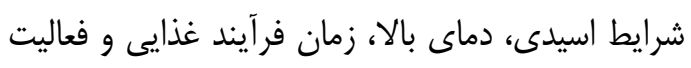

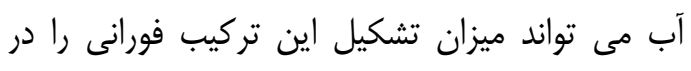

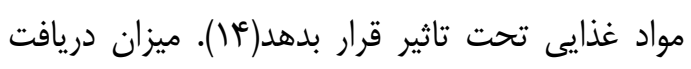

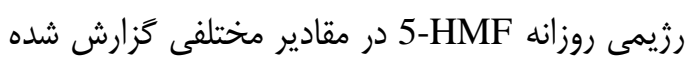
است(1) (1).

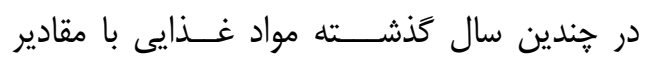
5-HMF

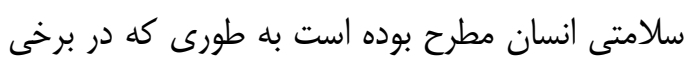

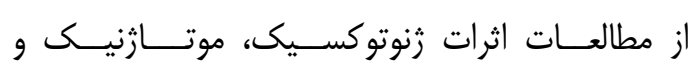

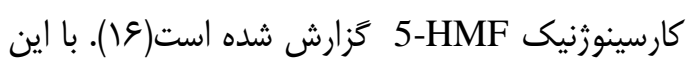
وجود، مطالعاتى هم وجود داشته است كه اثرات مضر ذكر شده را تاييد نكرده اند. در مطالعه انجام شده توسط هيج (National Toxicology Program) NTP كَونه اثرات نئويلاستيك در بافت هاى مختلف حيوانات كه در معرض دوزهاى مختلف 5-HMF قرار كرفته

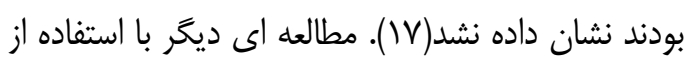

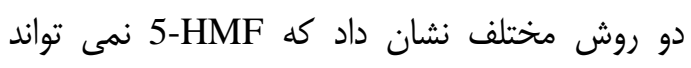
اثرات كارسينوزنيك داشته باشد(1) (1).

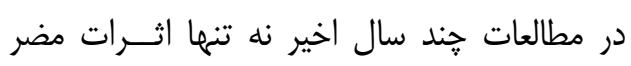
5-HMF فورانى بيشتر آشكار شده است. زاوو و همكاران اين

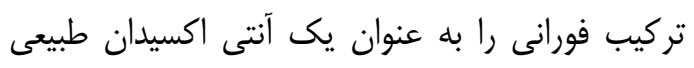
مطرح كردند كه مى تواند در شيمى درمانى بـ بران براى بيماران سرطانى مورد استفاده قرار بخيرد(19) و اثرات

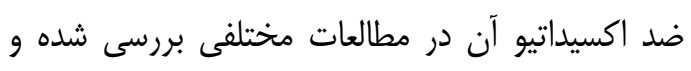

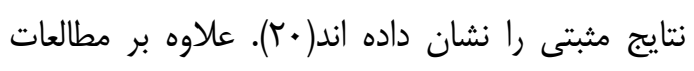

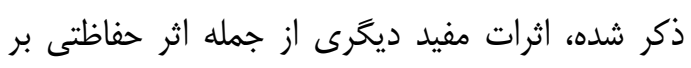

ميزان شيوع بيمارى هاى آلرزيك در دنيا در سه

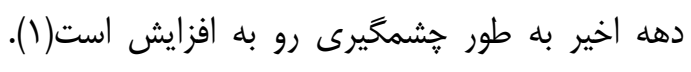

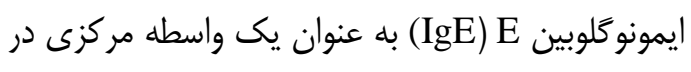

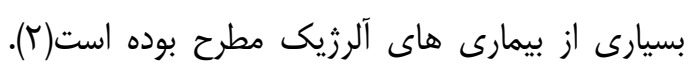

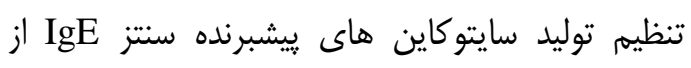
جمله راهكارهاى درمانى براى بيمارى هاى بآل آرزيك

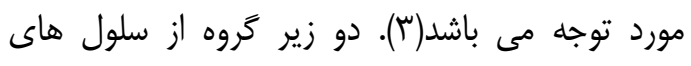

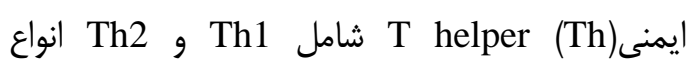
مختلفى از سايتوكاين ها را ترشح مى كنند. در ميان سايتوكاين هاى مترشحه از سلول هاى Th2، توجه

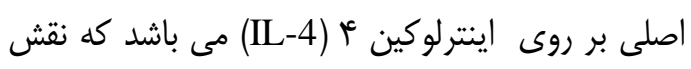
كليدى در سنتز IgE بر عمده دارد(أ). سلول IL-4 باعث تحريك و تمايز لنفوسيت ها،

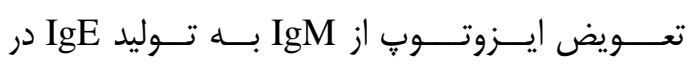
لنفـوسيت هاى B شده و در نتيجه نقش مهمى در القاء

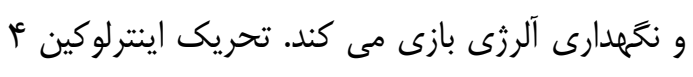

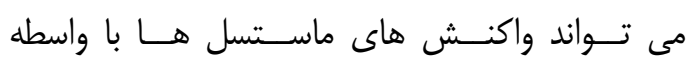

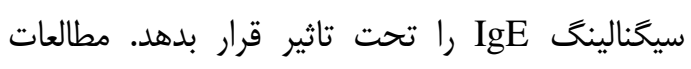

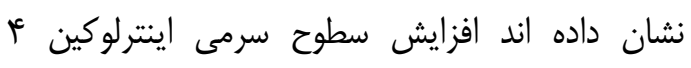

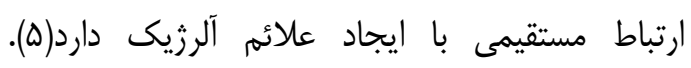

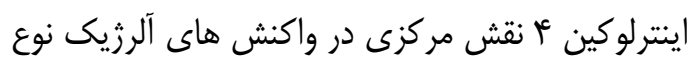
ا از طريق عمل كردن به عنوان يك واسطه در تمايز

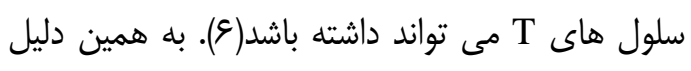

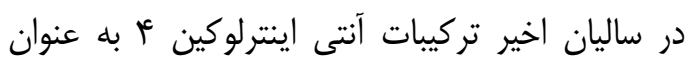
هدفى براى درمان بيمارى هاى مربوط به آلرئ آلرئي

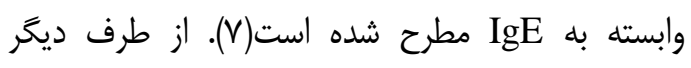

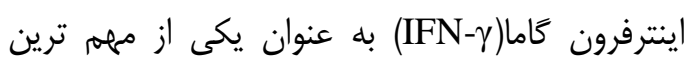
سايتوكاين هاى توليدى از سلول هاى Th1 در ايمنى إينى

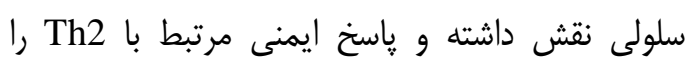

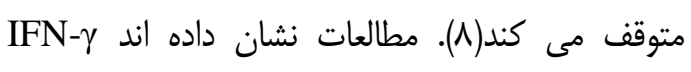
نقش بسيار مهمى در واكنش هاى آلرزيك وابسته بـ مانه

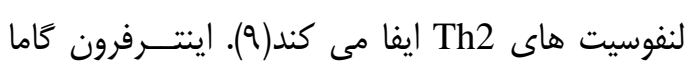

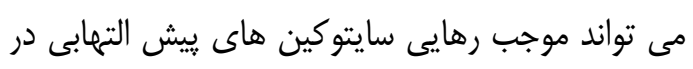

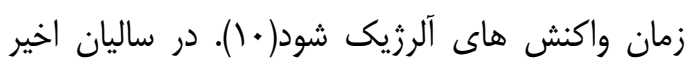

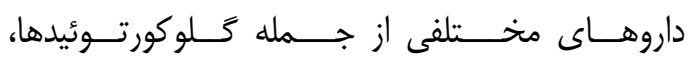

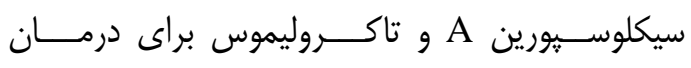

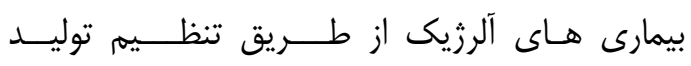


نحوه تهيه بليت هاى خوراكى حاوى 5-HMF

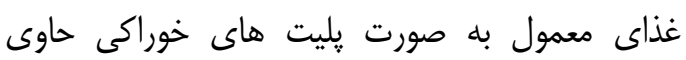

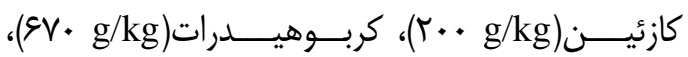

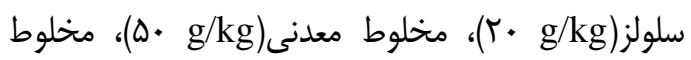

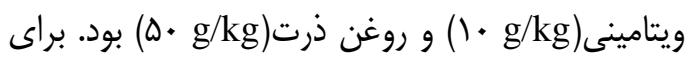

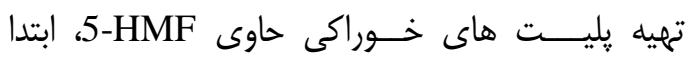

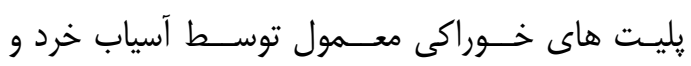
دوزهاى مشخص 5-HMF خريدارى شده Scientific, Pontiac Business Center Drive كه توسط ترازوى ديجيتال به طور (Elgin, USA

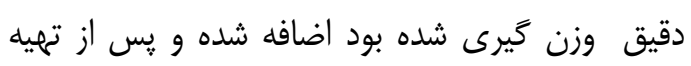

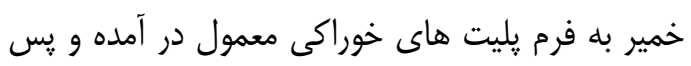

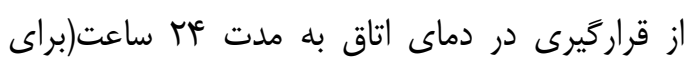

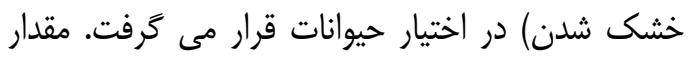

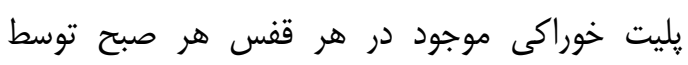

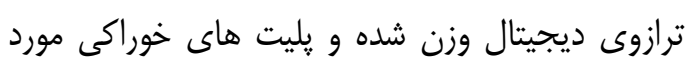
نياز در قفس هاى حيوانات قرار داده مى شد.

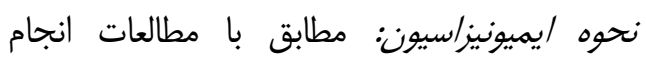

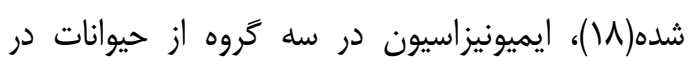

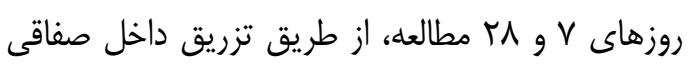

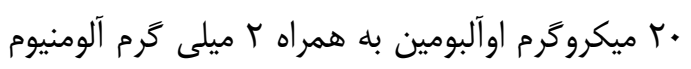

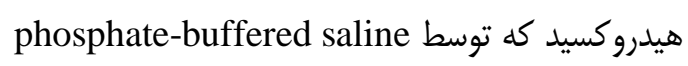
تا حجم ..1 (PBS)

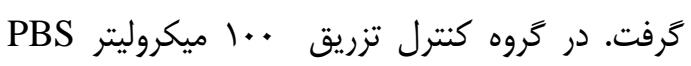
خالص انجام شد( شكل شماره (1).

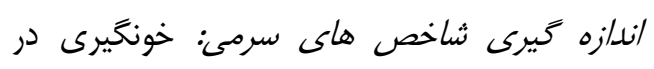

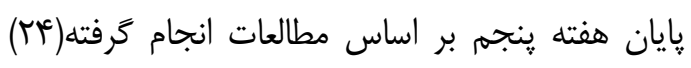

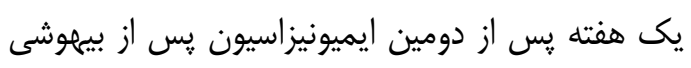

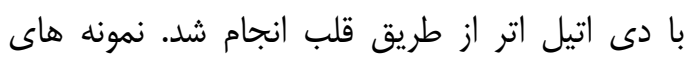

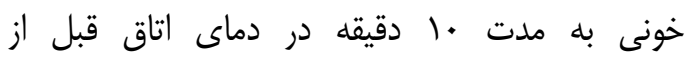

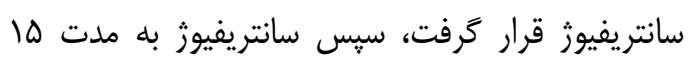

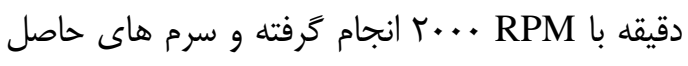

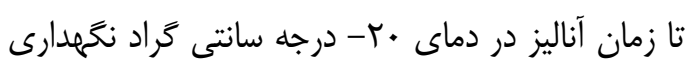

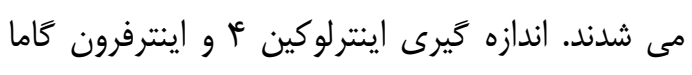

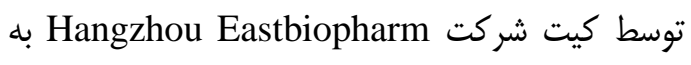

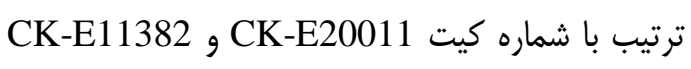
ساخت كشور جين به روش الايزا مطابق با دستورالعمل
روى نورون هاى عصبى(الr) توسط 5-HMF كزارش شده است.

بر برسى مطالعات اخيــر نشـان مى دهد 5-HMF

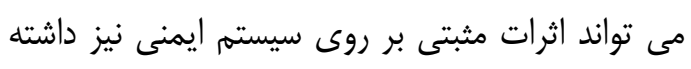

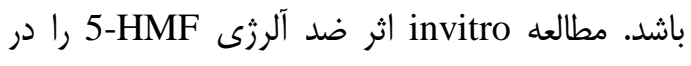

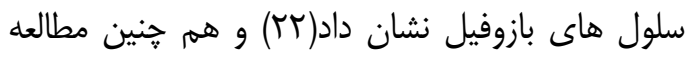

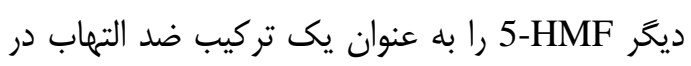

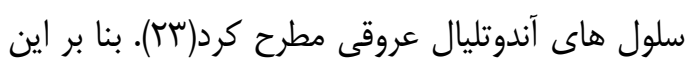

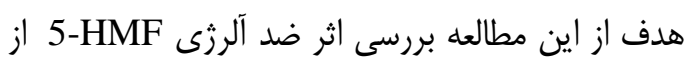

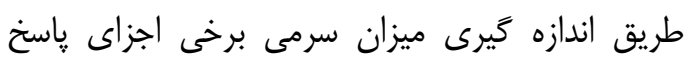

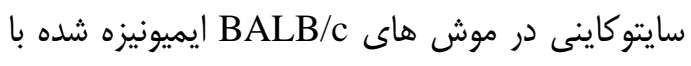
اوآلبومين مى باشد.

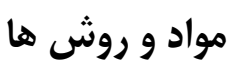
حيوانات: مطالعه حاضر بله صورت تجربـ مواتى در قالب

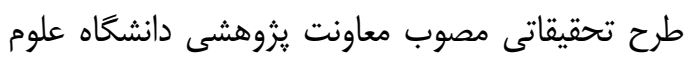

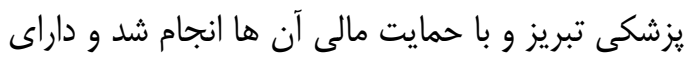

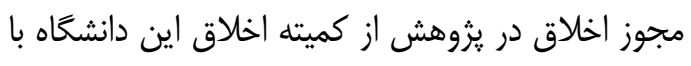

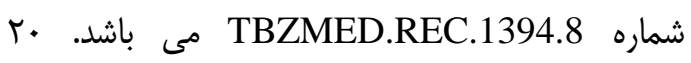

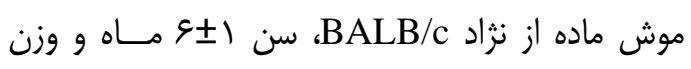

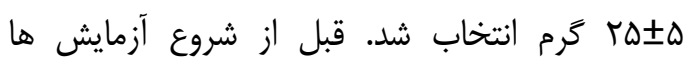

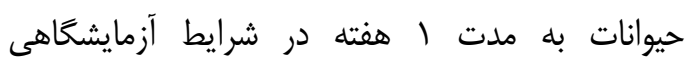

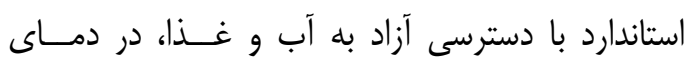

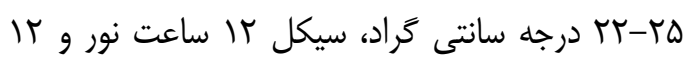

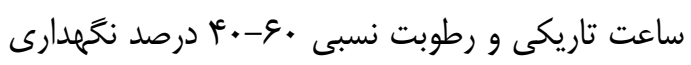
شدند. كروه بندى حيوانات: بعد از يكى هفته نتخهدارى

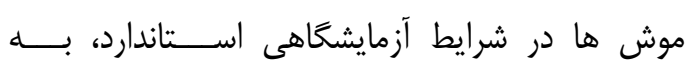

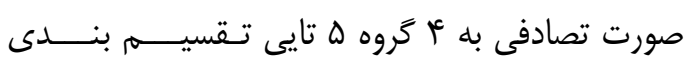

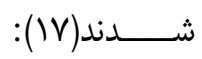
كروه كنترل: يليت هاى خوراكى معمول+تزريق PBS (phosphate-buffered saline) كروه مواجها: يليت هاى خوراكى معمول+تزريق او آلبومين

كروه LHMF: يليت هاى خوراكى حاوى 5-HMF تزريق اوآلبومين (MMmg/kgBw)

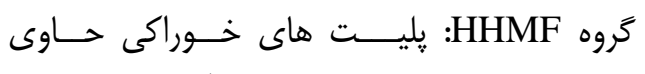
(VD.mg/kgBw) 5-HMF 


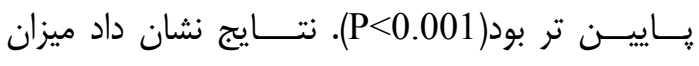

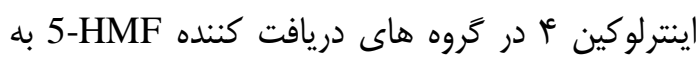

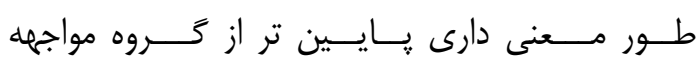

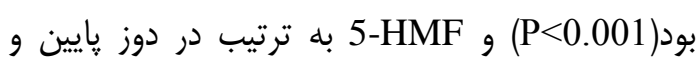

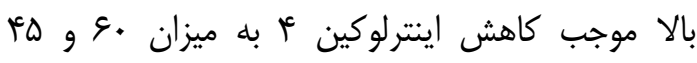
درصد شده بــود. تفــاوت معنى دارى بين بين ميانكَين

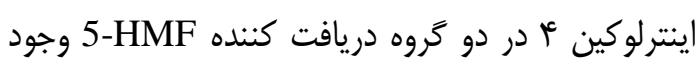
نداشت(P>0.05). ميانخين و انحراف معيار سطح سرمى اينترفرون كاما سرمى جهار تروه مورد بررسى در نمودار شماره ا ارائه

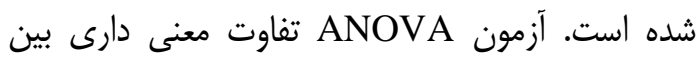

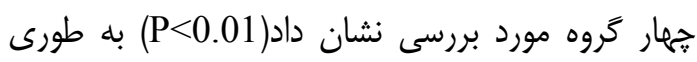

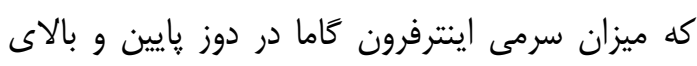

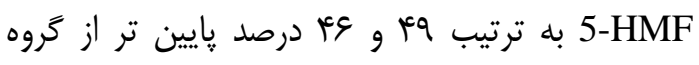
مواجها بود(P<0.05) هم جنين مقايسه ميانكَين ميزان

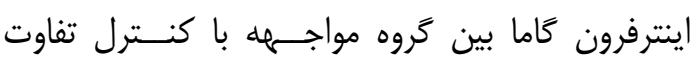

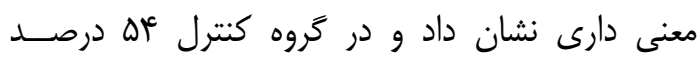

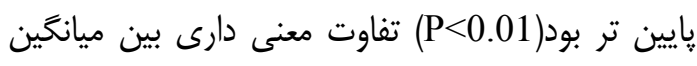

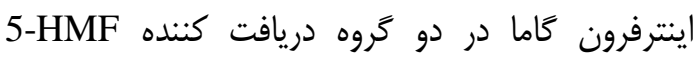
وجود نداشت(P>0.05).
كيت شركت سازنده با مقايسه جِال نورى نمونه هاى تست با منحنى استاندارد انجام شد. ميزان حساسيت

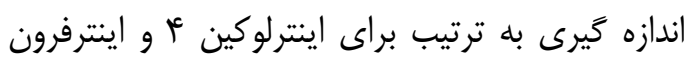

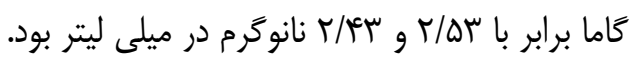

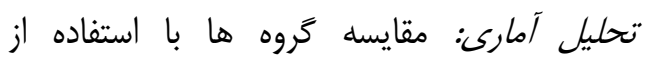
آناليز One-way ANOVA و تست تعقيبى Tukey

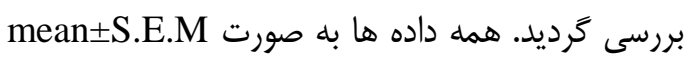

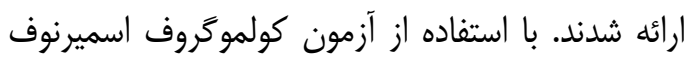
نرماليته داده ها به دست آمد. براى تمامى آنائن آناليزها، سطح معنى دارى P<0.05 در نظر كرفته شد.

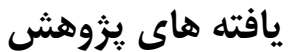

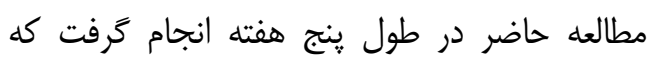

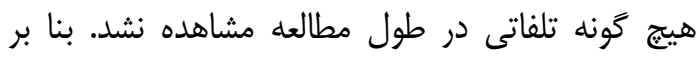

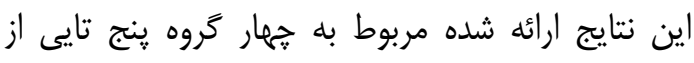

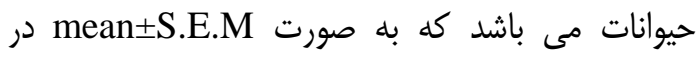
نمودار يك گزارش شده است. مقايسه ميانكين سطح سرمى اينترلوكين أ بين جهار

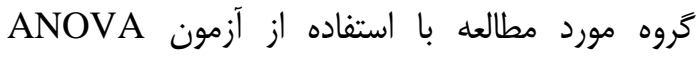

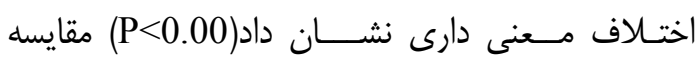
ميانكين ميزان اينترلوكين أ بين كروه مواجها داريه با كنترل

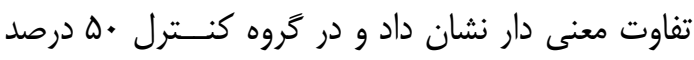

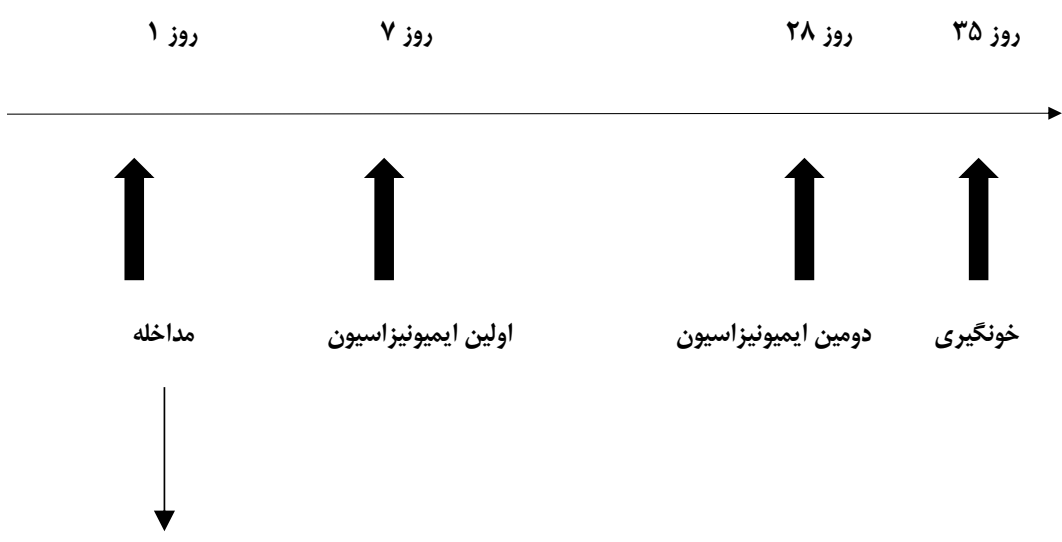

تروه كنترل: يليت هاى خوراكى معمول+تزريق كروه مواجهه: يِليت هاى خوراكى معمول+تزريق اوآلبومين كروه LHMF: يليت هاى خور اكى حاوى MM mg/kgBw ) 5-HMF) تزريق اوآلبومين كروه HHMF: يليت هاى خور اكى حاوى V- mg/kgBw) 5-HMF) + 

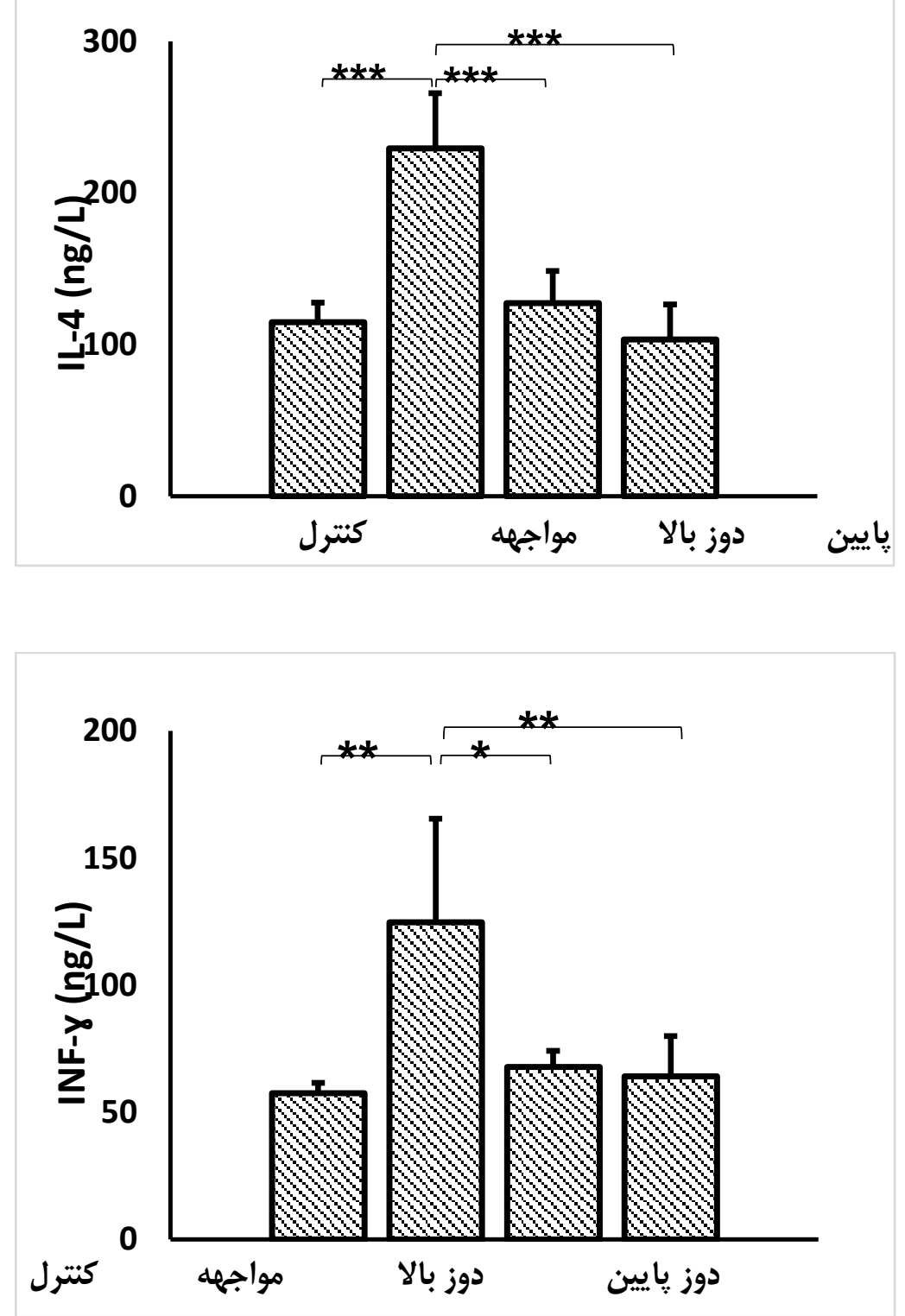

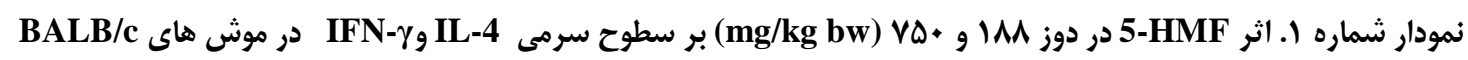

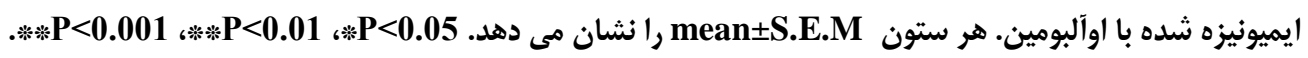

اينترلوكين f أنش مهمى در شروع واكنش هاى

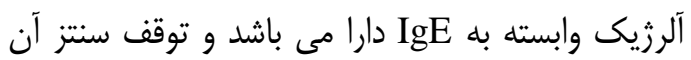
با كاهش توليد IgE همراه است(Tه). از طرف ديگر نتايج به دست آمده نشان داد ميزان اينترفرون كاما نيز

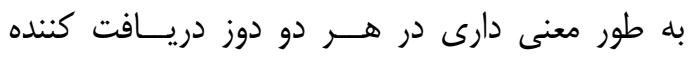

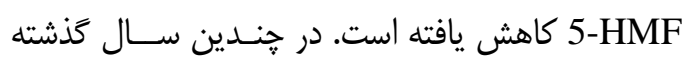
داروهاى مختلفى براى درمان بيمارى هاى آلرزيك از بافئ دان طريق تعديل سايتوكاين هاى ترشح شده از سلول هاى دراى
بحث و نتيجه كَيرى

در مطالعه حاضر، اثر 5-HMF دريجه دو دو دوز مختلف

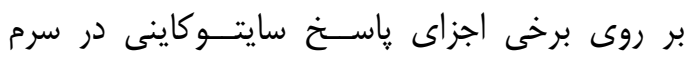
موش هاى BALB/c ايميونيزه شده با اوآلبومين مورد

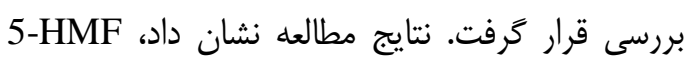
در هر دو دوز دريافتى موجب كاهش قرفي مابل توجه

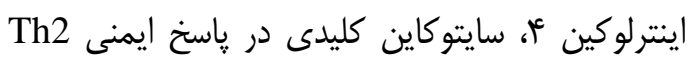
شد و افزايش دوز تاثير معنى دارى در نتايج نشان ندادئ 
حساس به ردوكس NF-kB قرار مى كيرد. توقف توليد NF-kB با كاهش سنتز بسيارى از سايتوكاين ها همراه

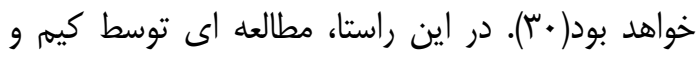

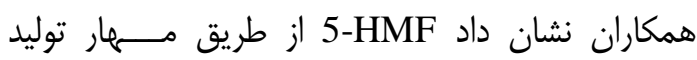
NF-kB مى تواند اثرات ضد التهابى داشته باشند(سٓ).

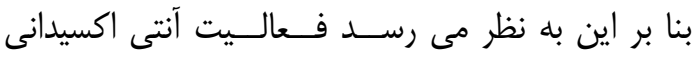

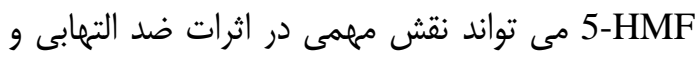
ضد آلرزى اين تركيب داشته باشد.

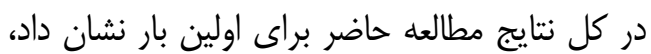
5-HMF مى تواند موجب كاهش توليد برخى از اجزاى نايج קاسخ سايتوكاينى Th1 و Th2 در سرم موش هاى BALB/c آينده مى تواند دستاوردهاى مهمى در زمينه استفاده از 5-HMF به عنوان مكمل يا داروى ضد آلرزى به دمانه دست آورد. هم جنين طبق نتايج اين مطالعه اين تركيب

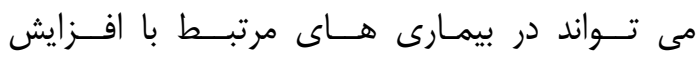

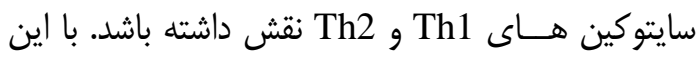
وجود مطالعات بيشترى براى بررسى مكانسيم دقيق تر و عوارض احتمالى ييشنهاد مى شود. سياسگزارى

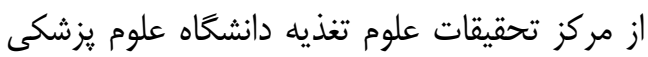

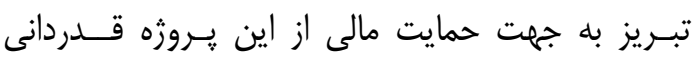

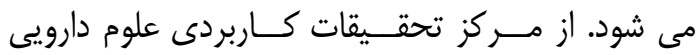

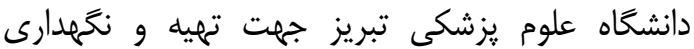

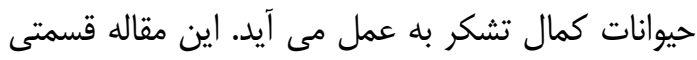

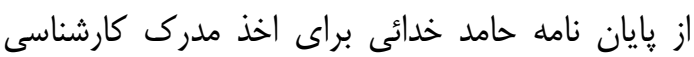
ارشد علوم تغذيه مى باشد.

\section{References}

1. Hansen T, Evjenth B, Holt J. Increasing prevalence of asthma allergic rhinoconjunctivitis and eczema among schoolchildren three surveys during the period 1985-2008. Acta Pediatr 2013;102: 47-52.

2.Menz G, Ying S, Durham SR, Corrigan CJ, Robinson DS, Hamid Q, et al. Molecular concepts of IgE-initiated inflammation in atopic and nonatopic asthma. Allergy 1998;53:15-21.

3.Barnes PJ. Cytokine modulators as novel
استفاده شده اند كه به دليل عوارض متعددى كه Th به همراه داشته اند با محدوديـت مصــرف رو به رو بله

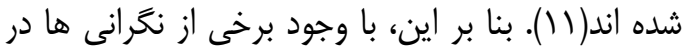

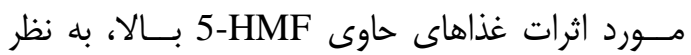
مى رسد اين تركيسب مى تــواند در تعــديل سايتوكاين هاى التهابى نقش مهمى ايفا كند.

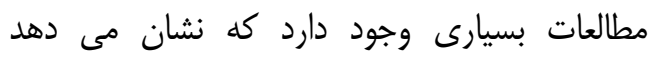

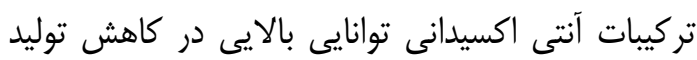
سايتوكاين هاى ترشح شده از سلول هاى Th دارند(ع). إندين مطالعه اخير اثرات آنتى اكسيدانى بررسى و اين تركيب را به عنوان يكى آنتى اكسيدان

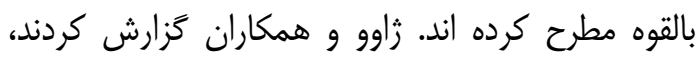
5-HMF موجب كاهش راديكال هاى آزاد مى شود و از طرف ديخر مـى تواند موجسب افزايسش آنزيم هاى

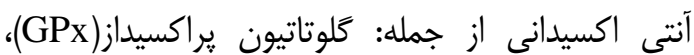

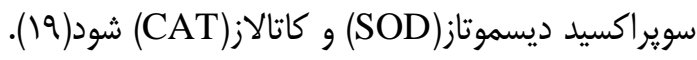
يراكسيداسيون ليبيدها و ارزيابى دفاع آنتى اكسيدانى در كران

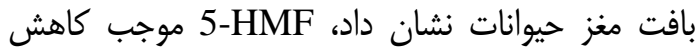

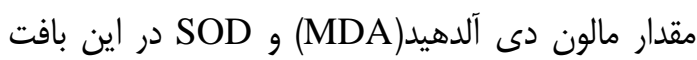
مى شود(TV) و موجب حفاظت از آسيب اكسيداتيو القاء

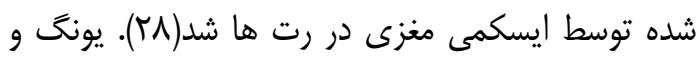

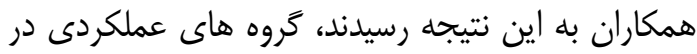
5-HMF شامل باندهاى دو أنه، اتم اكسيثن آلدهيدى

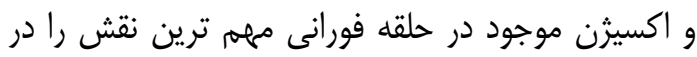

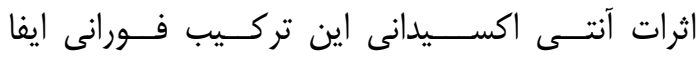
مى كنند(q). به نظر مى رسد مكانسيمى كه تركيبات

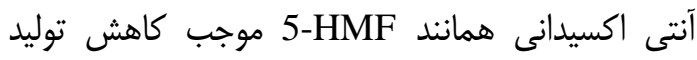
سايتوكاين ها مى شود تحت تاثير مهار فاكتور رونويسى همى

therapies for asthma. Annu Rev Pharmacol Toxicol R2002;42:81-98.

4. Kashiwada M, Deborah M, McKeag L, Murray K, Schröder A, Stephen M et al. IL4-induced transcription factor NFIL3/E4BP4 controls IgE class switching. Proc Natl Acad Sci USA 2009; 107: 81226.5

5. Saba MA, Akbari H, Banihashemian SM, Jazayeri H, Talaei SA, Banihashemian SH, et al. [Relationship between serum levels of IL-4 and IgE with disease severity in 
allergic asthma]. J Kashan Uni Medl Sci 2013; 17:366-72. (Persian)

6. Haas H, Falcone F, Holland M, Schramm G, Haisch K, Gibbs B. Early interleukin-4: its role in the switch towards a th2 response and IgE mediated allergy. Int Arch Allergy Immunol 2000; 119:86-94.

7. Schmidtweber CB. Anti-IL-4 as a new strategy in allergy. Chem Immunol Allergy 2012; 96:120-5.

8. Fietta P, Delsante G. The effector T helper cell triade. Riv Biol 2009; 102:6174.

9. Holgate S, Polosa R. Treatment strategies for allergy and asthma. Nat Rev Immunol 2008; 8:218-29.

10. Teixeira L, Fonseca B, Barboza B, Viola $J$. The role of interferon- $\gamma$ on immune and allergic responses. Mem Ins. Oswaldo Cruz 2005; 100: 137-44.

11. Dubus JC, Marguet C, Deschildre A, Mely L, Le Roux P, Brouard J, et al. Local side effects of inhaled corticosteroids in asthmatic children influence of drug dose age and device. Allergy2001;56:944-8.

12. Yong G, Zhang Y, Ying J. Efficient catalytic system for the selective production of 5-hydroxymethylfurfural from glucose and fructose. Angew Chem 2008; 120: 9485-88.

13. Gokmen V, Senyuva H. Improved method for the determination of hydroxymethylfurfural in baby foods using liquid chromatography-mass spectrometry. J Agric Food Chem 2006; 54: 2845-49.

14. Ghadimi SS, Alizadeh M, Esfanjani AT, Hezaveh SJG, Vayghan HJ. Assessement of dietary exposure to 5hydroxymethylfurfural from traditional iranian flat breads. Ital J Food Sci 2014;26:169-73.

15. Rufianhenares JA, Cueva SP. Assessment of hydroxymethylfurfural intake in the Spanish diet. Food Addit Contam 2008; 25:1306-12.

16. Capuano E, Fogliano V. Acrylamide and 5-hydroxymethylfurfural a review on metabolism toxicity occurrence in food and mitigation strategies. Food Sci Technol 2011;44:793-810.

17. Program NT. NTP toxicology and carcinogenesis studies of 5-hydroxymethyl2-furfural in F344/N Rats and B6C3F1 Mice gavage studies. Nat Toxicol Prog Tech Rep Ser 2010; 554:7-12.
18. Michail K, Matzi V, Maier A, Herwig $\mathrm{R}$, Greilberger J, Juan $\mathrm{H}$, et al. Hydroxymethylfurfural an enemy or a friendly xenobiotic? Anal Bioanal Chem 2007;387:2801-14.

19. Zhao L, Chen J, Su J, Li L, Hu S, Li B, et al. Invitro antioxidant and antiproliferative activities of 5hydroxymethylfurfural. J Agr Food Chem2013;61:10604-11.

20. Cao G, Cai H, Cai B, Tu S. Effect of 5hydroxymethylfurfural derived from processed Cornus officinalis on the prevention of high glucose-induced oxidative stress in human umbilical vein endothelial cells and its mechanism. Food Chem 2013;140: 273-9.

21. Liu A, Zhao X, Li H, Liu Z, Liu B, Mao $X$, et al. 5-Hydroxymethylfurfural an antioxidant agent from Alpinia oxyphylla Miq. improves cognitive impairment in $A \beta$ 1-42 mouse model of Alzheimers disease. Int Immunopharmacol 2014;23: 719-25.

22. Yamada P, Nemoto M, Shigemori H, Yokota S, Isoda $\mathrm{H}$. Isolation of 5hydroxymethyl furfural from Lycium chinense and its inhibitory effect on the chemical mediator release by basophilic cells. Planta Med 2011;77:434-37.

23. Kim HK, Choi Y, Lee EN, Park JK, Kim S, Park D, et al. 5Hydroxymethylfurfural from black garlic extract prevents tnfo-induced monocytic cell adhesion to HUVECs by suppression of vascular cell adhesion molecule-1 expression reactive oxygen species generation and NF- $\kappa \mathrm{B}$ activation. Phytother Res 2011;25:965-74.

24. Satter MA, Sakai K, Ahmed S, Yoshino K, Yamamoto S, Shimizu Y, et al. Lowprotein diet induces oral tolerance to ovalbumin in mice. J Nutr Sci Vitaminol Tokyo2002; 48:51-8.

25. Redpath S, Heieis G, Perona G. Spatial regulation of IL-4 signalling invivo. Cytokine2015; 75:51-6

26. Tripathi P, Nair S, Arora N. Supplementation of antioxidants glutathione and $\alpha$-lipoic acid attenuates oxidative stress and $\mathrm{Th} 2$ response in allergic airway inflammation. Indian $\mathrm{J}$ Allergy Asthma Immunol 2013;27:19-23.

27. Ya B, Zhang L, Zhang L, Li Y, Li L. 5hydroxymethyl-2-furfural prolongs survival and inhibits oxidative stress in a mouse 
model of forebrain ischemia. Neural Regen Res 2012;7:1722-28.

28. Zhang JH, Di Y, Wu LY, He YL, Zhao T, Huang $X$, et al. 5-HMF prevents against oxidative injury via APE/Ref-1. Free Radic Res 2015;49:86-94.

29. Li YX, Li Y, Qian ZJ, Kim MM, Kim SK. In vitro antioxidant activity of 5-HMF isolated from marine red alga Laurencia undulata in free-radical-mediated oxidative systems. J Microbiol Biotechnol 2009;19:1319-27.

30. Checker R, Sandur SK, Sharma D, Patwardhan RS, Jayakumar S, Kohli V, Potent anti inflammatory activity of ursolic acid a triterpenoid antioxidant is mediated through suppression of NF- $\mathrm{KB}, \mathrm{AP}-1$ and NF-AT. PLosone 2012;7:313-18. 


\title{
Cytokine Responses in BALB/c Mice Immunized with Ovalbumin after Oral Administration of 5-Hydroxymethylfurfural
}

\author{
Alizadeh $M^{1}$, Khodaei $H^{2 *}$
}

(Received: August 15, 2016

Accepted: February 4, 2017)

\begin{abstract}
Introduction: 5-Hydroxymethylfurfural (5HMF) is one of the most important products of the Millard reaction. Several kinds of food and beverage produce high amount of 5-HMF. In the recent years many profitable effects of this compound have been demonstrated. Because of the role of $\mathrm{T}$ helper cells cytokines in the inflammatory responses, this study sought to investigate the effects of 5-HMF on IFN- $\gamma$ and IL-4 levels respectively as Th1 and Th2 cytokines in $\mathrm{BALB} / \mathrm{c}$ mice immunized with ovalbumin (OVA).
\end{abstract}

Materials \& methods: BALB/c mice $(\mathrm{n}=5$ for each group) were grouped as follow: control, vehicle, and two different treatment groups. The treatment groups received daily doses of 188 and $750 \mathrm{mg} / \mathrm{kg}$ body weight, respectively). The groups were immunized with OVA on days 7 and 28 except for the controls. Interleukin 4(IL-4) and interferon gamma (IFN- $\gamma$ ) levels were measured in serum by ELISA.

Findings: IL-4 levels were significantly suppressed in 5-HMF treatment groups $(\mathrm{P}<0.001)$. IFN- $\gamma$ levels were significantly lowered in the treatment groups $(\mathrm{P}<0.05)$. Further, no significant difference was observed in IL- 4 and IFN- $\gamma$ levels between treatment groups $(\mathrm{P}>0.05)$.

Discussion \& conclusions: 5-HMF reduced production of selected components of Th1 and Th2 cytokine responses in immunized $\mathrm{BALB} / \mathrm{c}$ mice.

Keywords: $\quad$ 5-Hydroxymethylfurfural, Cytokine, Ovalbumin

1. Nutrition Research Center, Tabriz University of Medical Sciences, Tabriz, Iran

2. Student Research Center, Faculty of nutrition, Tabriz, University of Medical Sciences, Tabriz, Iran

* Correspondin author Email: hamedkhodaeii@yahoo.com 